We agree that all surgeons who have used uncemented knee replacements must follow up their patients carefully, and we advocate that revision be undertaken before bone stock is lost.

Y.-H. KIM, MD

Joint Replacement Center of Korea

Seoul, Korea.

Kim YH. Knee arthroplasty using a cementless PCA prosthesis with a porous-coated central tibial stem: clinical and radiographic review at five years. J Bone Joint Surg [Br] 1990:72-B:412-7.

\section{MEASUREMENT OF FEMORAL VEIN BLOOD FLOW DURING THR}

Sir,

In their article in the November 1994 issue entitled 'Measurement of femoral vein blood flow during total hip replacement' (1994;76-B:918-21) Warwick et al state that cementless total hip replacement carries less risk of thrombosis and refer to a study done on Koreans by Kim and Suh (1988). I have been unable, however, to find any statement supporting such an opinion in this article. Kim and Suh state that the primary determinant responsible for the low incidence ( $10 \%$ ) of deep-vein thrombosis (DVT) in their study is not the cementless prosthesis but its use in Koreans. There are several other studies which indicate that the incidence of DVT is not as high in some areas of the world as in western populations (Chan and Hoaglund 1980; Atichartakarn et al 1988; Esemenli et al 1992: Aktan et al 1995).

Wolf, Hozack and Rothman (1993) referred to Kim and Suh's study incorrectly and I have already drawn attention to this (Esemenli 1995). The variability of the incidence of DVT in different populations is not well known and references are not read in detail by authors. The misleading title of Kim and Suh's study, as indicated by Hoaglund (1989), appears responsible for the repeated misinterpretation.

B. T. ESEMENLI, MD

Marmara University Hospital

Istanbul, Turkey.

Aktan AO, Gunal O, Biren T, Yegen C, Yalin P. Low incidence of deep venous thrombosis after laparoscopic cholecystectomy. J Hepatobilianpancreatic Surg 1995:in press.

Atichartakarn V, Pathepchotiwong K, Keorochana S, Eurvilaichit C. Deep venous thrombosis after hip surgery among Thai. Arch Int Med 1988; 148:1349-53.

Chan CW, Hoaglund FT. Pulmonary thromboembolism and venous thrombosis in the Chinese. Clin Orthop 1980:150:253-60.

Esemenli T, Güven O, Karahan M, Gündes H, Gürmen N. Postoperative deep vein thrombosis following emergency and elective hip surgery. In: Progress in angiology 1991. Torino: Edizioni Minerva Medica, 1992:223-5.

Esemenli T. Pulmonary embolism in total joint arthroplasty (Letter). Clin Orthop 1995:in press.
Hoaglund FT. Low incidence of deep venous thrombosis after cementless total hip replacement (Letter). J Bone Joint Surg [Am] 1989;71-A:151.

Kim YH, Suh JS. Low incidence of deep venous thrombosis after cementless total hip replacement. J Bone Joint Surg [Am] 1988; 70-A:878-82.

Warwick D, Martin AG, Glew D, Bannister GC. Measurement of femoral vein blood flow during total hip replacement. J Bone Joint Surg [Br] 1994;76-B:918-21.

Wolf LD, Hozack WJ, Rothman RH. Pulmonary embolism in total joint arthroplasty. Clin Orthop 1993;288:219-33.

Author's reply:

Sir,

I entirely agree that the title of Kim and Suh's article is misleading, since the authors' conclusion was that Asian race, rather than the uncemented implant, was the reason for the low incidence of deep-vein thrombosis (DVT). It is intriguing that racial factors may partially determine the predisposition to DVT. This suggests a genetic or environmental contribution, and there is therefore the prospect of identifying or modifying the risk in predisposed individuals. Nevertheless, a report on North American patients by Francis and colleagues (1986) suggested a reduced risk of thrombosis in those having uncemented rather than cemented prostheses, although the randomisation in the study was between dextran and heparin, rather than between cemented and uncemented hip replacements.

In our article we suggested that cementless hip replacement requires less prolonged distortion of the femoral vein. A more important factor may be the cement itself since there is evidence that methylmethacrylate (MMA) cement is thrombogenic. Acrylic monomer leaches into the circulation after injection and veins experimentally incubated with MMA show endothelial cell derangement (Dahl et al 1994). Trauma to bone and implantation of prostheses using bone cement induce activation of coagulation and fibrinolytic shutdown (Dahl et al 1993).

A randomised study comparing cemented with uncemented hip replacements using DVT as the main outcome measure would confirm whether cement increases the risk, but I am not aware that such a study exists.

\section{J. WARWICK. FRCS}

University of Bristol

Bristol, UK.

Dahl OE, Pedersen T, Kierulf P, et al. Sequential intrapulmonary and systemic activation of coagulation and fibrinolysis during and after total hip replacement surgery. Thromb Res 1993;70:451-8.

Dahl OE, Aspelin T, Lyberg T. Bone trauma and methylmethacrylate monomer (MMA) in the pathogenesis of femoral deep vein thrombosis following cemented hip replacement. Proc EORS 1994;4:56.

Francis CW, Marder VJ, Evarts CM. Lower risk of thromboembolic disease after THR with non-cemented than with cemented prostheses. Lancet 1986;1:769-71. 